\title{
Penile implant infection factors: a contemporary narrative review of literature
}

\author{
Bryce A. Baird^, Kevin Parikh, Gregory Broderick \\ Mayo Clinic Florida, Jacksonville, FL, USA \\ Contributions: (I) Conception and design: All authors; (II) Administrative support: BA Baird, G Broderick; (III) Provision of study materials or \\ patients: BA Baird, K Parikh; (IV) Collection and assembly of data: BA Baird, K Parikh; (V) Data analysis and interpretation: BA Baird, K Parikh; (VI) \\ Manuscript writing: All authors; (VII) Final approval of manuscript: All authors. \\ Correspondence to: Bryce A. Baird, MD. Mayo Clinic Florida, 4500 Sand Pablo Road, Jacksonville, FL 32224, USA. Email: baird.bryce@mayo.edu.
}

\begin{abstract}
Objective: We aim to review and summarize published literature that features implanted penile devices and details infection of these devices as a complication. In particular, we will detail the factors that influence infection of penile implants.

Background: Types of penile prostheses (PP) include inflatable implants and semirigid implants; these are utilized for treatment of erectile dysfunction. Likely the most feared complication of penile implants is infection. There are a handful of factors that are implicated in device infection.

Methods: Searches were performed using MEDLINE and PubMed databases using keywords and phrases 'penile implant AND infection'; 'penile prosthesis AND infection'; 'penile implant infection'. We have presented results from our literature search. We divided these into 'Surgical Elements' and 'Patient Selection and Factors.' Each topic is discussed in its own section.

Conclusions: Strides have been made since the initial penile prosthesis (IPP) surgeries to improve infection rates including diabetes control, antibiotic coating of devices, and antibiotic implementation. Going forward, more studies, especially randomized control trials, need to focus on defining levels of diabetic control (sugar control and A1C control), determining the role of metabolic syndrome in infection promotion and determining laboratory values which could be predictive of infection. We present a discussion of important factors to consider in the realm of PP infections. In addition, we include studies which discuss topics for future directions in decreasing the number of infections seen with PP.
\end{abstract}

Keywords: Penile prosthesis (PP); infection; inflatable penile prosthesis (IPP); antibiotic

Submitted Jun 26, 2021. Accepted for publication Aug 27, 2021.

doi: 10.21037/tau-21-568

View this article at: https://dx.doi.org/10.21037/tau-21-568

\section{Introduction}

Penile prosthesis (PP) placement represents a safe and effective surgical option for erectile dysfunction. Penile prostheses are comprised of two groups-inflatable and noninflatable devices. These groups include several different models such as the malleable, single-, two-, and three-piece inflatable devices; an excellent summary of these devices can be found in a paper by Chung (1). PP placement is subject to several complications including bowel or bladder injury, mechanical device failure and the most significant complication-infection. In cases of infection, patient morbidity, financial burden and device removal are often incurred (2). Signs and symptoms of these infections include prolonged implant pain, adhesion of the pump contents to skin or other tissues, masses around implant contents,

^ ORCID: 0000-0003-2937-1801. 
draining tracts, and wound separation (3). We aim to discuss factors which increase and decrease rates of infection in PP surgery; additionally, we cover some factors that have been studied in regards to infection but show no impact on infection rates $(3,4)$. We present the following article in accordance with the Narrative Review checklist (available at https://dx.doi.org/10.21037/tau-21-568).

\section{Methods}

A literature review was performed using PubMed and Ovid MEDLINE databases. No limits were placed on publication years. Articles had to be published in peer reviewed journals to be included. Keyword searches including 'penile prosthesis' AND 'infection'; 'inflatable penile prosthesis' OR 'IPP' AND 'infection'; 'penile implant' AND 'infection'; 'penile implant infection risk'; 'penile prosthesis infection risk.' On final review, papers from 1992-2021 were included in our paper. We included 80 studies in our review. Factors increasing, decreasing and not effecting infection rates were reviewed and analyzed.

\section{Results and discussion narrative}

Our results yielded many infection factors. We included results that notably decreased infection rates. We also included results which can increase infection rates. In addition, we included some unique studies which address topics of interest such as climate and the use of local anesthetics as sections which favor themselves toward future directions in decreasing PP infections. The topics discussed along with a grading of their effect on penile prosthesis infections can be found in Table 1 .

\section{Pre-surgical scrub}

Pre-surgical preparation of surgical sites is crucial for decreasing infection risk during surgery, particularly in implant cases. There seems to be no benefit of a traditional 10 -minute scrub versus newer 90 -second chlorhexidine scrub sticks or alcohol-based solutions (5). This study did not look specifically at PP and infection rates. We still utilize a prolonged scrub followed by scrubbing with chlorhexidine scrub sticks.

One prospective randomized control trial compared chlorhexidine to povidone-iodine for surgical preparation scrub before genitourinary prosthesis surgery (6). This study noted positive post-preparation cultures in $8 \%$ of chlorhexidine patients versus $32 \%$ of iodine patients $(\mathrm{P}=0.0091)$ but noted no clinically significant increased risk of infection due to these cultures. This study still concluded that chlorhexidine would be the superior scrub agent. Several other studies have shown superiority of chlorhexidine surgical scrub over iodine; of note chlorhexidine is used in our practice (7-9). Aside from presurgical scrub, the use of mupirocin and chlorhexidine have been implemented for 5 days prior to surgery and shown to treat Staph aureus colonization in the nares and to decrease surgical site infections $(3,10)$. These studies were largely from orthopedic surgery, general surgery and neurosurgery cohorts.

\section{Preoperative \& perioperative antibiotics}

There are definite benefits to single-dose preoperative antibiotics $(11,12)$. However, there are not randomized control trials in the field of urology to explore the benefit of preoperative antibiotics; instead, we can rely on orthopedic and general surgery literature in the setting of implants and mesh use $(13,14)$. Antibiotics can include first-line prophylaxis with an aminoglycoside plus 1st/2nd generation cephalosporin or vancomycin. There are certain acceptable alternatives including but not limited to ampicillin/sulbactam (15). Our institution generally utilizes an aminoglycoside plus vancomycin. In addition, we utilize antibiotic solutions during our prosthesis placements. It was shown than the vast majority of penile prosthesis surgeons use some sort of antibiotic irrigation perioperatively/ intraoperatively (16). A large multi-center review of 932 patients revealed significantly lower rates of infection when using a gentamycin plus vancomycin dipping solution compared to all other dipping solutions (17).

\section{Postoperative antibiotics}

Despite the American Urological Association's (AUA) best practice statement on antimicrobial prophylaxis suggesting antimicrobial prophylaxis be discontinued 24 hours following penile prosthesis surgery, a high percentage of urologists discharge patients on an outpatient course of postoperative antibiotics (16). Postoperative antibiotic prophylaxis is based mainly on historical practice rather than data from the literature. In fact, two recent studies have suggested no decrease in postoperative infections with postoperative antibiotics for inflatable penile prosthesis (IPP). In a recent study from Vanderbilt 
Table 1 Evidence table for link to infections in penile prosthesis surgery

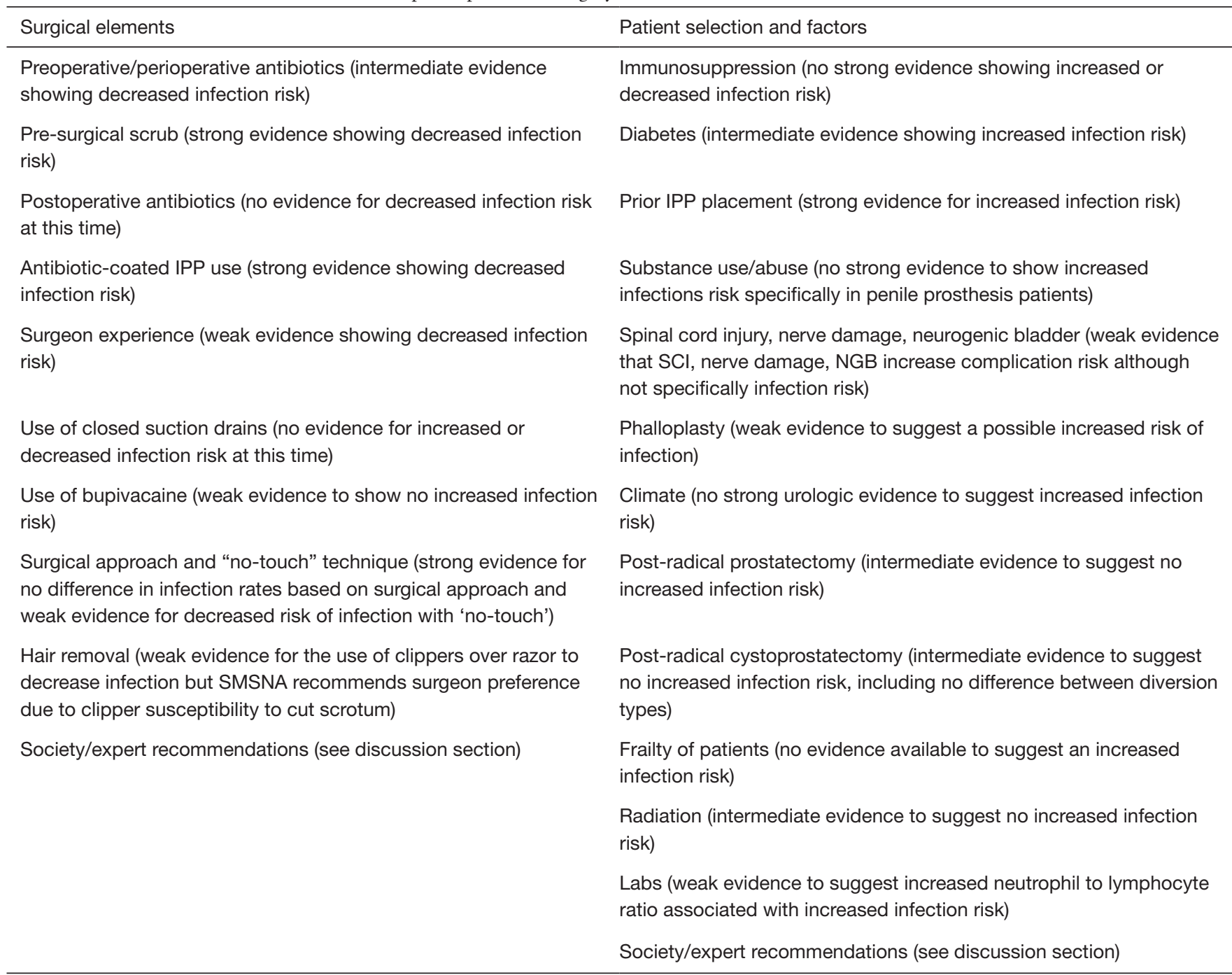

IPP, inflatable penile prosthesis; SCI, spinal cord injury; NGB, neurogenic bladder.

University, three groups were analyzed-one was given no postoperative antibiotics and had no risk factors for infectious complication. This group was compared to a group of patients who had infectious risk factors but was not given antibiotics and to a group which had risk factors and was given postoperative antibiotics. There were no differences in infection. Median follow-up for these patients was 4.6 months. Rates of explantation and non-operative infectious complications were tracked $(0 \%$ vs. $4 \%$ vs. $5 \%$, $\mathrm{P}=0.130$ and $1 \%$ vs. $2 \%$ vs. $2 \%, \mathrm{P}=0.829)$. These results were not statistically significant in difference (18). Another study reviewed post-operative antibiotic prescription trends for IPP and artificial urinary sphincter (AUS). Researchers from this study did not find significant evidence that explant rates differed among patients receiving postoperative antibiotics for IPP (antibiotics vs. no antibiotics IPP: $2.2 \%$ vs. $1.9 \%, \mathrm{P}=0.18$ ). This group also looked at individual classes of antibiotics and determined no decreased odds of explant with any particular antibiotic (19).

\section{Antibiotic-coated IPP use}

Advances in IPP design from industry leaders Boston Scientific (headquartered in Marlborough, Massachusetts) and Coloplast (headquartered in Humlebaek, Denmark) have led to decreased infection rates via use of antibiotic 
coatings (20-22). Boston Scientific's AMS 700 IPP contains InhibiZone ${ }^{\mathrm{TM}}$ technology, an antibiotic-impregnated IPP with minocycline and rifampin (23). Coloplast Titan ${ }^{\circledR}$ IPPs come with a hydrophilic coating so when the prosthesis is dipped into an aqueous solution of antibiotic prior to implantation, the coating absorbs the antibiotic (24-26). Lipsky et al. found that increased prevalence of antibioticcoated IPPs correlated with improved infection-free survival rates in both diabetic $(\mathrm{P}<0.001)$ and non-diabetic patients $(\mathrm{P}<0.001)(27)$. A systematic review of 14 clinical studies evaluated noncoated versus coated IPPs. Noncoated IPPs showed increased infection rates compared to coated IPPs $(2.32 \%$ vs. $0.89 \%, \mathrm{P}<0.01)(20,28)$. To further evaluate the efficacy of coated prosthesis, Jani et al. performed a multicenter trial which analyzed bacterial cultures of the prosthesis at time of revision surgery (29). Four groups were studied [non-infected patients with uncoated penile prostheses $(\mathrm{n}=133)$, non-infected patients with coated penile prostheses $(n=75)$, infected patients with uncoated penile prosthesis $(\mathrm{n}=16)$, and infected patients with coated PPs $(\mathrm{n}=12)]$. Of the non-infected patients, positive cultures were found in 85 patients with uncoated PPs versus 32 patients with coated PPs $(\mathrm{P}=0.004)$. There was no significant difference in positive cultures for the infected groups, but these groups also had far fewer patients than the noninfected groups.

\section{Surgeon experience}

Surgeon experience and volume are factors which have become popular topics of study. In particular, there have been a handful of papers studying surgeon experience as well as standardized operative technique in the field of penile prosthesis implantation $(30,31)$. One retrospective study compared the first 20 IPP surgeries of a surgeon to the last 48 surgeries in a 68 -patient series. Complication rates were higher in the first 20 surgeries compared to the last 48 surgeries $(\mathrm{P}=0.043)$ (32). This would indicate that a minimum number of 20 surgeries are necessary to attain a level of experience to decrease rates of infection, although other arbitrary numbers could be studied and produce similar statistics. In addition, there is some data that suggests shorter operative times might be associated with decreased complications (3). Another recent prospective study analyzed 309 patients who had IPP placement with resident involvement (33). Only one patient was noted to have an infection which is notably lower than the expected rate of infection $(1-3 \%)$. This study was utilized to promote
IPP surgery at an academic institution which would utilize the help/assistance of surgeons/surgeons-in-training who may not have as much experience as some attending physicians.

Henry et al. compared a center of excellence to a multiplesurgeon group performing penile prosthesis surgery (34). Although they did not stratify complications, they noted 8 iatrogenic failures in the multi-surgeon group (which were classified as infection, erosion or poor position) that led to removal of prosthesis. The center of excellence had no such complications $(\mathrm{P}<0.05)$. The New York Statewide Planning and Research Cooperative System database has been analyzed for infectious complications (35). Multivariable analysis showed that compared to surgeons performing >31 IPPs per year, surgeons performing 0-2 cases per year were 2.5 times more likely to require reoperation for infection. Surgeons performing 3-7 cases per year were 2.4 times more likely to perform reoperation due to infection, and surgeons performing 8-31 IPP surgeries per year were 2.1 times more likely to perform reoperation for infection. As mentioned above, arbitrary numbers have been studied as minimum numbers of surgeries to decrease infection rates; this study suggests that surgeons must perform greater than 31 cases per year to significantly decrease infectious complications in penile prosthetic surgery.

\section{Use of closed suction drains}

A relative lack of data exists on the use of drains in penile prosthesis surgery and their effect on infections rates. One group found no increased risk of infection in patients who have closed-suction drains placed in three-piece IPP surgery. They found a $3.3 \%$ infection rate in patients $(\mathrm{n}=425)$ receiving a closed-suction drain (36).

\section{Use of bupivacaine}

The use of local anesthetic is common in surgical practice. In particular, bupivacaine has been studied in relation to penile prosthesis implantation. One basic science study compared the growth of bacteria around InhibiZone which is on the AMS700 implant versus the growth around the Titan Coloplast. Specifically, this study compared the ability of the antibiotic dip to perform with and without bupivacaine. Growth of both $S$. epidermidis and E. coli at 24 and 48 hours of incubation was inhibited in all implants without any extra bacterial growth promoted by bupivacaine. The authors of this paper indicated that the 
use of bupivacaine does not affect the protective effects of antibiotic dips and can safely be used during penile prosthesis surgery pending clinical trials (37). This basic science study has been somewhat applied in a clinical fashion during a study performed by Ghanem et al. (38). This retrospective review studied local anesthetic use in 117 penile prosthesis cases. No prosthesis infections occurred in this study, and only 8 minor skin infections were noted. These results align with the laboratory study which suggests that bupivacaine can be utilized as a local anesthetic without increasing risk of infection.

\section{Surgical approach and "no-touch" technique}

Variations in surgical approaches have been studied to ascertain if infection risks can be reduced. The two most common surgical incision approaches for the placement of IPP are either through a penoscrotal or infrapubic approach. An early study explored infection rates among prosthesis through both the penoscrotal and infrapubic approaches. The study did not reveal any statistical significance with a $2.9 \%$ infection rate in 139 infrapubic implants versus a $0.9 \%$ infection rate in 221 peno-scrotal implants $(\mathrm{P}=0.15)$. (39) A large systematic review published in 2018 reviewed 22 studies comparing infection rates between 3-piece penoscrotal IPP insertion versus 3-piece infrapubic insertion and concluded no evidence that surgical incision strategy reduces infection risk (40).

Eid et al. coined a "no-touch technique" to eliminate contact of the prosthesis with the patient's skin (41). This approach is accomplished through a combination of surgical glove changes, surgical equipment discarding, and by draping the operative field with a plastic drape and operating though a small opening in the drape. Results of their study showed a reduction in infection risk from $5.3 \%$ in patients without infection-retardant coated implants to about $1.99 \%$ in patients who had implants with coatings. When the 'no-touch' technique was used with the infection-retardant coated implants, the infection rate dropped to about $0.46 \%$ (41).

\section{Hair removal}

Hair removal around the scrotum and suprapubic region is commonly performed by surgeons before prosthesis placement. The Sexual Medicine Society of North America recommends surgeons have their choice of razors or clippers for hair removal before penile prosthesis surgery due to a statement that scrotal rugae are more susceptible to cuts by clippers than regular skin (42). A 14-trial Cochrane review investigated hair removal before surgery and its relation to infection rates (43). This analysis resulted in no significant difference between studies that compared hair removal with no hair removal with the qualifier that this comparison was underpowered. Shaving with razors was shown to have increased rates of surgical site infections compared to hair removal with clippers. When comparing hair removal the day of surgery versus the day before surgery, no differences were found in infection rates.

\section{Immunosuppression}

There are obvious concerns regarding wound healing and infection in immunosuppressed patients. Sidi et al. showed no increased infection in 13 immunosuppressed men (44). Chronic steroid therapy was found to be a risk for infection after penile prosthesis placement with renal transplant showing no increased risk (22). Unfortunately, this study was quite small and only included 3 renal transplant patients. One larger study showed 46 organ transplant patients with similar infection rates to non-transplant patients (45). This is a more robust study and perhaps does suggest that transplant is not a major risk factor for postprosthesis infection.

\section{Diabetes}

Diabetics have long been considered high risk patients for penile prosthesis infections. One of the first studies looking at diabetic status and hemoglobin A1C levels (A1C levels) in penile prosthesis outcomes was published in 1992. This prospective study of 90 patients noted 5 patients with infections (46). All 5 infections occurred in diabetic patients. In addition, diabetic patients were stratified into 2 groups (one group with $\mathrm{A} 1 \mathrm{C}>11.5 \%$ and one group with A1C $<11.5 \%)$. Four patients with infections were in the higher A1C group with only one patient in the lower A1C group $(\mathrm{P}<0.0003)$; this led early researchers to determine an $\mathrm{A} 1 \mathrm{C}$ of $11.5 \%$ as a cutoff value for pursuing elective penile prosthesis placement.

Wilson et al. performed two studies, one retrospective (47) and one prospective (48). The retrospective study also noted similar differences of $3 \%$ infection rate in diabetic patients versus $1 \%$ in non-diabetic patients although this was not found to be statistically significant. Initially, the prospective study noted a non-significant difference of $7.5 \%$ infection rate in diabetic patients versus $3.3 \%$ in non-diabetic patients. 
After a follow-up editorial, which almost doubled the study size, diabetic patients had a higher infection rate compared to non-diabetic patients ( $7.7 \%$ vs. $3.3 \%, \mathrm{P}=0.036)$.

A national database of over 10,000 men undergoing IPP implantation was reviewed to determine factors associated with device explantation. Device explantation occurred in 228 patients (2.1\%). Diabetes (OR 1.59, 95\% CI: 1.14-2.21, $\mathrm{P}<0.01)$ was one of two factors associated with higher odds of explantation (19).

Lipsky et al. reviewed a New York state database and compared the outcomes of over 14,000 patients over a 20 -year span (27). Infectious complications were seen in $3 \%$ of diabetic patients versus $2 \%$ of non-diabetic patients $(\mathrm{P}<0.001)$. It should be noted that this study performed multivariate analysis to control for age, race, comorbidities, insurance, surgeon volume and era of antibiotic-coating to provide an overall hazard ratio of 1.32 for increased infection risk in patients who have diabetes $(\mathrm{P}=0.016)$.

Diabetics appear to be at increased risk of developing fungal infections. One study reviewed IPP explant rates in relation to fungal infections. Of 26 patients with fungal infections, 18 patients had diabetes $(69 \%)$, with a mean hemoglobin A1c (HbA1c) value of 8.4 (range, 5.8-13.3; median 7.5 ) (49). Additionally, the fungal infections were commonly found to involve Candida species. Given that obesity and diabetes seemed to be predisposing factors for fungal IPP infections, this study concluded that patients with such comorbidities may benefit from antifungal prophylaxis.

\section{Prior IPP placement}

Patients with a prior IPP should be considered high risk for infection (50). Prior IPP placement (OR 3.32, 95\% CI: $1.14-6.99, \mathrm{P}<0.01)$ was associated with higher $\mathrm{OR}$ of explantation. Specifically, any prior IPP, regardless of infection status, predisposed patients to needing an explantation relative to IPP-naïve patients (19). In addition compared to the $1-3 \%$ infection rate of initial penile implants, the risk of reinfection has been reported to be as high as $10 \%$ for all salvage cases (47). A small retrospective study of 44 patients with at least one prior IPP revealed increasing rates of infection in relation to number of revisions with the first revision having a $6.8 \%$ infection rate versus a $100 \%$ infection rate for the fifth revision $(51,52)$. Overall rates of infection were positively correlated with number of prior IPP-related surgeries performed $(\mathrm{P}<0.01)$.

\section{Substance use/abuse}

Substance use and abuse have been studied in regards to perioperative outcomes and complications. In a study of 602 surgical patients, an infection rate of $2 \%$ was found (53). Five of the twelve infected patients were found to be actively overusing or abusing at least one substance at the time of their operation. It was determined that polysubstance abuse, poorly controlled blood sugar, and homelessness at the time of prosthesis placement were all three positively correlated with infections. Smoking, specifically, has been studied in penile prosthesis surgeries. Smoking has been noted as a risk factor for glans necrosis after implantation (54). Poor blood supply and necrosis are commonly linked to infection. There have been many general studies showing increased risk of infection and perioperative complications in patients who are smokers $(55,56)$. One large meta-analysis revealed a surgical site infection odds ratio of 1.79 in smokers versus non-smokers as well as reduced infection (odds ratio 0.43 ) in patients who stopped smoking at least 4 weeks before their operation (57). While there is an overall paucity of data specific to smoking and its impact on infection in penile prosthesis surgery, one retrospective review noted no significant increase in infection rates in patients who were smokers (58). Another review noted smoking as a risk factor for revision or removal surgery in penile prosthesis patients; while this study did not specifically look at infection rates relative to smoking, revisions/explantations are often treatments for infection so one could infer from this data that infection was likely involved (59). Of note, society recommendations generally lean toward smoking cessation before prosthesis implantation (60).

\section{Spinal cord injury, nerve damage, and neurogenic bladder}

Xuan et al. reviewed 35 patients (28 with paraplegia and 7 with traumatic nervi erigentes) and only noted one infection in this group of patients receiving IPP (61). Paraplegia has been linked to increased risk of infection (58). Dave $e t$ al. explored the risk associated with neurogenic bladder on complication rate. This study showed a $24.3 \%$ overall rate of complication (infection, erosion, or mechanical failure) in the NGB cohort compared with a $7.5 \%$ rate in the nonneurogenic control group $(\mathrm{P}=0.001)$. On multivariate logistic regression modeling, NGB (OR 3.47; 95\% CI: $1.13-10.71 ; \mathrm{P}=0.03)$ was independently associated with risk of IPP complication. This statistic does not necessarily breakdown the risk of infection but does show a higher 
complication rate. It should be noted the most common cause of NGB was spinal cord injury (62). Patients who have to use self-catheterization seem to have no change in surgical site infections (3).

\section{Phalloplasty}

Infection rates range from $4.7 \%$ to $33 \%$ in patients receiving phalloplasty (62-66). Most studies of prosthesis after phalloplasty are in the transgender population. However, one 15-patient phalloplasty cohort was studied after penile amputation for cancer. Seven of the fifteen patients underwent prosthesis placement with one patient incurring infection (67). No studies have evaluated the risk of infection in the implant-phalloplasty population compared to the population undergoing prosthesis insertion in their native penis. However, the infection ranges published thus far are notably higher in patients who have undergone phalloplasty with subsequent prosthesis placement. One study of prosthesis insertion in 247 patients with phalloplasty revealed an $8.5 \%$ infection rate. After multivariate analysis, age, phalloplasty type, and several other factors were shown to have no significant value for predicting infection risk (68).

\section{Climate}

Climate's effect on infection rates has been studied by the orthopedic community but minimally but the urology community. Only one study reviewed climate trends in relation to prosthesis infection; infections occurred more commonly in June $(n=24)$ and less frequently during the winter months $(\mathrm{n}=39)$, with the lowest number occurring in March ( $\mathrm{n}=11)$. One-hundred thirty-nine infections occurred at average daily temperatures greater than $55^{\circ} \mathrm{F}$, compared to 72 infections at less than $55^{\circ} \mathrm{F}$. The incidence rate ratio for this trend was $1.93(\mathrm{P}<0.001)$. Fungal infections were found to correlate with daily humidity (increased humidity equals increased infections). Infected implants performed in the fall and summer were over 3 and 2.3 times, respectively, more likely to grow gram-positive bacteria compared to implants performed in spring $(\mathrm{P}=0.004 ; \mathrm{P}=0.039)$ (69). Climate study in penile prosthesis patients is novel and is likely an important consideration for future studies.

\section{Post-radical prostatectomy}

Radical prostatectomy for prostate cancer can undoubtedly cause erectile dysfunction (70). One study compared 58 post-radical prostatectomy patients and 59 vasculogenic erectile dysfunction patients and noted no significant difference in infection rates between the two groups (71). Yiou and Binhas prospectively studied patients receiving a penile prosthesis and urinary sphincter after radical prostatectomy (72). This small studied revealed zero infectious complications in penile prosthesis patients and determined that implantation of both urinary sphincter devices and penile prostheses in prostatectomy patients is both safe and feasible. Cleveland Clinic reviewed 115 post-prostatectomy patients who received IPPs and noted a $2.6 \%$ infection rate, concluding that patients can safely receive penile prostheses after prostatectomy (73). As noted above, a variety of studies note a low infection risk for patients undergoing penile prosthesis placement after prostatectomy.

\section{Post-radical cystoprostatectomy}

Post-cystectomy patients often deal with erectile dysfunction as a complication of their surgery (74). Loh-Doyle et al. studied 80 patients who had IPP placement after radical cystectomy (RC) with urinary diversion (75). This study showed 4 infections total in the group. Infections were studied in relation to diversion type, radiation history, chemotherapy regimen, presence of AUS, presence of diabetes, age, and presence of hypertension which revealed no significant differences in infection rates. Of note, diversion types studied included neobladder, ileal conduit, and continent cutaneous diversion. Falcone et al. (68) reviewed 43 patients who received a 3 -piece IPP or semirigid device after cystoprostatectomy; infection only occurred in one of these patients. A study of patients who specifically underwent RC with orthotopic neobladder diversion and subsequent placement of both an IPP and AUS revealed a low infection rate (39 patients, 1 IPP infection) (76).

\section{Frailty of patients}

The modified frailty index has been studied and shown to be of no predictive value for complications or infection in penile prosthesis implants (77). Secondary outcomes of this study did show association of $\mathrm{HbA1C}$, dyslipidemia, hypertension, Peyronie's disease, and duration of procedure with increased risk of infection. In addition, age greater than 75 years seems to show no increased risk of infection $(3,77)$. One other 
Table 2 ICSM penile implant infection recommendations

ICSM made recommendations on decreasing the rate of infections (42)

4a. For penile implant surgery, no definitive recommendations can be made regarding preoperative site cleansing protocol and optimization of patient's hemoglobin A1c. Level of evidence 4, strength of recommendation C

4b. Preoperative antibiotics with gram-positive and gram-negative coverage should be given with therapeutic antibiotic levels attained before making the surgical incision. Level of evidence 2 , strength of recommendation $B$

4c. Shaving vs. clipping to remove scrotal hair is left to the surgeon's discretion with an objective to avoid traumatic skin disruptions. Level of evidence 4, strength of recommendation $\mathrm{C}$

4d. Whenever available, surgeons should use alcohol-based skin preparations in the operating room as the operative site scrub. Level of evidence 1 , strength of recommendation $A$

4e. Techniques to minimize skin and device contact can decrease IPP infection rates. Level of evidence 3, strength of recommendation $\mathrm{C}$

ICSM, The International Consultation on Sexual Medicine; IPP, inflatable penile prosthesis.

particular condition which could lead to frailty of patients would be HIV infection. Currently there is no evidence that HIV status or even other chronic immunosuppressive states influence infection risk in IPP patients (3).

\section{Radiation}

Overall, there are few studies which review the effects of radiation in patients receiving penile prosthesis. Loh-Doyle et al. reviewed 78 patients who underwent 3-piece IPP placement after treatment with pelvic radiation (external beam radiation and or brachytherapy) (78). Only 2 patients in this group developed infectious complication which aligns with percentages of infection from most other studies leading these authors to conclude that IPP placement after radiation is not a risk factor for infection. The cohort of 78 patients is a good sample size and gives objective evidence of infection rates comparable to patients who have not had radiation. Other studies support this group's findings $(47,79)$.

\section{Labs}

Preoperative lab studies are often used to obtain baseline characteristics of patients. One novel lab test [neutrophil to lymphocyte ratio (NLR)] could be an important emerging value according to a recent study. Of 153 patients, $11.8 \%$ of patients had infectious complications with a mean NLR statistically higher than those patients without infectious complications. This study determined that a cutoff preoperative NLR of 6.2 would offer $67 \%$ sensitivity and $99 \%$ specificity in predicting early postoperative infection (within one year of penile implant placement) (80). While this is not a commonly used lab value in clinical practice, it is important to consider NLR in terms of future directions for avoiding infections.

\section{Society/expert panel recommendations}

The European Society for Sexual Medicine notes diabetes as a risk factor and recommends optimizing glycemic control to normal A1C levels before surgery to decrease the rate of infection; in addition, they make recommendations on other topics listed above (60).

The International Consultation on Sexual Medicine (ICSM) has recommendations outlined in Table 2 (42). We have presented these in table format for simplicity of reading. A systematic review that was part of the 2018 AUA guidelines noted 91 articles reporting infectious adverse events. Prosthetic infection rates ranged from $0 \%$ to $24.6 \%$ while inflatable penile prostheses displayed a wider range $(0-24.6 \%)$ than malleable devices $(0-9.1 \%)$; the most frequently reported infection rate for inflatable devices was $5 \%$ or less. Infection rates of diabetic patients were noted to be similar to the rates of non-diabetic patients in the most current studies; in addition, no glycosylated hemoglobin cutoff was found to infer increased or decreased risk of prosthesis infection (81).

\section{Summary}

We present a novel narrative review that highlights many important factors to consider when addressing the risk of infection in penile prosthesis surgery. It is worth noting several techniques we utilize to reduce infection risk in patients undergoing penile prosthesis placement. 
Preoperatively we perform a urinalysis and culture on every patient scheduled for penile prosthesis placement. We treat any positive culture and ensure negative results before proceeding with surgery. Additionally, perioperative antibiotics are ordered in our preoperative clinic. These antibiotics generally consist of vancomycin and gentamicin.

After patient positioning, hair removal is accomplished with the utilization of a razor to avoid skin abrasions like those seen with the use of clippers. The external genitalia are prepared with a 5 -minute chlorhexidine scrub followed by chlorhexidine paint preparation with 2 sticks. The chlorhexidine is allowed to dry for 3 minutes as suggested by its manufacturer. After proper draping of the patient, we immediately place a urinary catheter to empty the bladder. We place the catheter in standard sterile fashion, and we utilize a miniature chlorhexidine stick to re-prep the catheter distal to the meatus once it settles at the bladder neck. This technique for chlorhexidine prep of the catheter is attributed to Dr. Eugene Rhee.

We utilize an antibiotic dipping solution as has been outlined in previous studies (17). A vancomycin/gentamicin combination has been shown to be the most efficacious and the most commonly used. We use our solution to submerge instruments before using them and to bathe components of penile prostheses before implantation. Additionally, we use our solution to wash our hands between steps. Finally, we use our solution in a bulb irrigator to rinse the penile prosthesis as it is being placed. Double-gloving is always utilized during penile prosthesis placement at our institution and the outside gloves are changed before and after steps that involve manipulation of the prosthesis.

In general, we limit penile prosthesis cases to one surgeon and two residents at maximum. Additionally, we only have on scrub tech and one circulating nurse and on anesthesia provider once the prep of the patient has occurred and no one is to enter or leave the room.

Strides have been made since the initial penile prosthesis surgeries to improve infection rates including diabetes control, antibiotic coating of devices, and antibiotic implementation. Going forward, more studies, especially randomized control trials, need to focus on defining levels of diabetic control (sugar control and A1C control), determining the role of metabolic syndrome in infection promotion and determining laboratory values which could be predictive of infection.

Overall, there is a paucity of level 1 evidence to guide penile prosthesis surgery in regards to infection. Between the existing studies and guidelines set forth by the ICSM, the AUA and the other urologic governing bodies there are strong guides to avoid infection and decrease infection rates.

\section{Acknowledgments}

Funding: None.

\section{Footnote}

Reporting Checklist: The authors have completed the Narrative Review checklist. Available at https://dx.doi. org/10.21037/tau-21-568

Peer Review File: Available at https://dx.doi.org/10.21037/ tau-21-568

Conflicts of Interest: All authors have completed the ICMJE uniform disclosure form (available at https://dx.doi. org/10.21037/tau-21-568). The authors have no conflicts of interest to declare.

Ethical Statement: The authors are accountable for all aspects of the work in ensuring that questions related to the accuracy or integrity of any part of the work are appropriately investigated and resolved.

Open Access Statement: This is an Open Access article distributed in accordance with the Creative Commons Attribution-NonCommercial-NoDerivs 4.0 International License (CC BY-NC-ND 4.0), which permits the noncommercial replication and distribution of the article with the strict proviso that no changes or edits are made and the original work is properly cited (including links to both the formal publication through the relevant DOI and the license). See: https://creativecommons.org/licenses/by-nc-nd/4.0/.

\section{References}

1. Chung E. Penile prosthesis implant: scientific advances and technological innovations over the last four decades. Transl Androl Urol 2017;6:37-45.

2. Montague DK, Angermeier KW, Lakin MM. Penile prosthesis infections. Int J Impot Res 2001;13:326-8.

3. Köhler TS, Nikhil GK, Wilson SK. Wilson's: Pearls, perils and pitfalls of penile prosthesis surgery. Fort Smith: Calvert McBride Publishers, 2018.

4. Holland B, Kohler T. Minimizing Penile Implant Infection: A Literature Review of Patient and Surgical 
Factors. Curr Urol Rep 2015;16:81.

5. Tsai JC, Lin YK, Huang YJ, et al. Antiseptic Effect of Conventional Povidone-Iodine Scrub, Chlorhexidine Scrub, and Waterless Hand Rub in a Surgical Room: A Randomized Controlled Trial. Infect Control Hosp Epidemiol 2017;38:417-22.

6. Yeung LL, Grewal S, Bullock A, et al. A comparison of chlorhexidine-alcohol versus povidone-iodine for eliminating skin flora before genitourinary prosthetic surgery: a randomized controlled trial. J Urol 2013;189:136-40.

7. Kava BR, Kanagarajah P, Ayyathurai R. Contemporary revision penile prosthesis surgery is not associated with a high risk of implant colonization or infection: a singlesurgeon series. J Sex Med 2011;8:1540-6.

8. Darouiche RO, Wall MJ Jr, Itani KM, et al. ChlorhexidineAlcohol versus Povidone-Iodine for Surgical-Site Antisepsis. N Engl J Med 2010;362:18-26.

9. Paocharoen V, Mingmalairak C, Apisarnthanarak A. Comparison of surgical wound infection after preoperative skin preparation with $4 \%$ chlorhexidine correction of chlohexidine and povidone iodine: a prospective randomized trial. J Med Assoc Thai 2009;92:898-902.

10. George S, Leasure AR, Horstmanshof D. Effectiveness of Decolonization With Chlorhexidine and Mupirocin in Reducing Surgical Site Infections: A Systematic Review. Dimens Crit Care Nurs 2016;35:204-22.

11. Dropkin BM, Kaufman MR. Antibiotics and Inflatable Penile Prosthesis Insertion: A Literature Review. Sex Med Rev 2021;9:174-80.

12. Pineda M, Burnett AL. Penile Prosthesis Infections-A Review of Risk Factors, Prevention, and Treatment. Sex Med Rev 2016;4:389-98.

13. Boxma H, Broekhuizen T, Patka P, et al. Randomised controlled trial of single-dose antibiotic prophylaxis in surgical treatment of closed fractures: the Dutch Trauma Trial. Lancet 1996;347:1133-7.

14. Yerdel MA, Akin EB, Dolalan S, et al. Effect of singledose prophylactic ampicillin and sulbactam on wound infection after tension-free inguinal hernia repair with polypropylene mesh: the randomized, double-blind, prospective trial. Ann Surg 2001;233:26-33.

15. Wolf JS Jr, Bennett CJ, Dmochowski RR, et al. Best practice policy statement on urologic surgery antimicrobial prophylaxis. J Urol 2008;179:1379-90.

16. Wosnitzer MS, Greenfield JM. Antibiotic patterns with inflatable penile prosthesis insertion. J Sex Med 2011;8:1521-8.

17. Towe M, Huynh LM, Osman MM, et al. Impact of
Antimicrobial Dipping Solutions on Postoperative Infection Rates in Patients With Diabetes Undergoing Primary Insertion of a Coloplast Titan Inflatable Penile Prosthesis. J Sex Med 2020;17:2077-83.

18. Dropkin BM, Chisholm LP, Dallmer JD, et al. Penile Prosthesis Insertion in the Era of Antibiotic StewardshipAre Postoperative Antibiotics Necessary? J Urol 2020;203:611-4.

19. Adamsky MA, Boysen WR, Cohen AJ, et al. Evaluating the Role of Postoperative Oral Antibiotic Administration in Artificial Urinary Sphincter and Inflatable Penile Prosthesis Explantation: A Nationwide Analysis. Urology 2018;111:92-8.

20. Mandava SH, Serefoglu EC, Freier MT, et al. Infection retardant coated inflatable penile prostheses decrease the incidence of infection: a systematic review and metaanalysis. J Urol 2012;188:1855-60.

21. Wilson SK, Salem EA, Costerton W. Anti-infection dip suggestions for the Coloplast Titan Inflatable Penile Prosthesis in the era of the infection retardant coated implant. J Sex Med 2011;8:2647-54.

22. Wilson SK, Zumbe J, Henry GD, et al. Infection reduction using antibiotic-coated inflatable penile prosthesis. Urology 2007;70:337-40.

23. Boston Scientific. Available online: https://www. bostonscientific.com/content/dam/bostonscientific/ uro-wh/general/ams/Resources/AMSUSED-00743InhibiZone_Brochure-2.4.15-FINAL.pdf

24. Coloplast. Available online: https://www.coloplast.us/titantouch-en-us.aspx

25. Dhabuwala C. In vitro assessment of antimicrobial properties of rifampin-coated Titan(®) Coloplast penile implants and comparison with Inhibizone(®). J Sex Med 2010;7:3516-9.

26. Dhabuwala $\mathrm{C}$, Sheth $\mathrm{S}$, Zamzow B. Infection rates of rifampin/gentamicin-coated Titan Coloplast penile implants. Comparison with Inhibizone-impregnated AMS penile implants. J Sex Med 2011;8:315-20.

27. Lipsky MJ, Onyeji I, Golan R, et al. Diabetes Is a Risk Factor for Inflatable Penile Prosthesis Infection: Analysis of a Large Statewide Database. Sex Med 2019;7:35-40.

28. Wilson SK, Costerton JW. Biofilm and penile prosthesis infections in the era of coated implants: a review. J Sex Med 2012;9:44-53.

29. Jani K, Smith C, Delk JR 2nd, et al. Infection Retardant Coatings Impact on Bacterial Presence in Penile Prosthesis Surgery: A Multicenter Study. Urology 2018;119:104-8.

30. Hinds PR, Wilson SK, Sadeghi-Nejad H. Dilemmas of 
inflatable penile prosthesis revision surgery: what practices achieve the best outcomes and the lowest infection rates? (CME). J Sex Med 2012;9:2483-91; quiz 2492.

31. King AB, Klausner AP, Johnson CM, et al. Expert training with standardized operative technique helps establish a successful penile prosthetics program for urologic resident education. J Sex Med 2011;8:2726-32.

32. Barrier A, Marcelli F, Villers A. Learning curve for inflatable penile prosthesis. Prog Urol 2019;29:947-54.

33. McAbee KE, Pearlman AM, Terlecki RP. Infection following penile prosthesis placement at an academic training center remains low despite involvement of surgeons-in-training. Investig Clin Urol 2018;59:342-7.

34. Henry GD, Kansal NS, Callaway M, et al. Centers of excellence concept and penile prostheses: an outcome analysis. J Urol 2009;181:1264-8.

35. Onyeji IC, Sui W, Pagano MJ, et al. Impact of Surgeon Case Volume on Reoperation Rates after Inflatable Penile Prosthesis Surgery. J Urol 2017;197:223-9.

36. Sadeghi-Nejad H, Ilbeigi P, Wilson SK, et al. Multiinstitutional outcome study on the efficacy of closedsuction drainage of the scrotum in three-piece inflatable penile prosthesis surgery. Int J Impot Res 2005;17:535-8.

37. Lokeshwar SD, Horodyski L, Lahorewala SS, et al. The Effect of Bupivacaine on the Efficacy of Antibiotic Coating on Penile Implants in Preventing Infection. Sex Med 2019;7:337-44.

38. Ghanem HM, Fahmy I, Fallon B. Infection control in outpatient unicomponent penile prosthesis surgery. Int J Impot Res 1999;11:25-7.

39. Garber BB, Marcus SM. Does surgical approach affect the incidence of inflatable penile prosthesis infection? Urology 1998;52:291-3.

40. Palmisano F, Boeri L, Cristini C, et al. Comparison of Infrapubic vs Penoscrotal Approaches for 3-Piece Inflatable Penile Prosthesis Placement: Do We Have a Winner? Sex Med Rev 2018;6:631-9.

41. Eid JF, Wilson SK, Cleves M, et al. Coated implants and "no touch" surgical technique decreases risk of infection in inflatable penile prosthesis implantation to $0.46 \%$. Urology 2012;79:1310-5.

42. Levine LA, Becher EF, Bella AJ, et al. Penile Prosthesis Surgery: Current Recommendations From the International Consultation on Sexual Medicine. J Sex Med 2016;13:489-518.

43. Tanner J, Norrie P, Melen K. Preoperative hair removal to reduce surgical site infection. Cochrane Database Syst Rev 2011;(11):CD004122.

44. Sidi AA, Peng W, Sanseau C, et al. Penile prosthesis surgery in the treatment of impotence in the immunosuppressed man. J Urol 1987;137:681-2.

45. Cuellar DC, Sklar GN. Penile prosthesis in the organ transplant recipient. Urology 2001;57:138-41.

46. Bishop JR, Moul JW, Sihelnik SA, et al. Use of glycosylated hemoglobin to identify diabetics at high risk for penile periprosthetic infections. J Urol 1992;147:386-8.

47. Wilson SK, Delk JR 2nd. Inflatable penile implant infection: predisposing factors and treatment suggestions. J Urol 1995;153:659-61.

48. Wilson SK, Carson CC, Cleves MA, et al. Quantifying risk of penile prosthesis infection with elevated glycosylated hemoglobin. J Urol 1998;159:1537-9; discussion 1539-40.

49. Gross MS, Reinstatler L, Henry GD, et al. Multicenter Investigation of Fungal Infections of Inflatable Penile Prostheses. J Sex Med 2019;16:1100-5.

50. Serefoglu EC, Mandava SH, Gokce A, et al. Longterm revision rate due to infection in hydrophilic-coated inflatable penile prostheses: 11-year follow-up. J Sex Med 2012;9:2182-6.

51. Montgomery BD, Lomas DJ, Ziegelmann MJ, et al. Infection risk of undergoing multiple penile prostheses: an analysis of referred patient surgical histories. Int J Impot Res 2018;30:147-52.

52. Zargaroff S, Sharma V, Berhanu D, et al. National trends in the treatment of penile prosthesis infections by explantation alone vs. immediate salvage and reimplantation. J Sex Med 2014;11:1078-85

53. Balen A, Gross MS, Phillips EA, et al. Active Polysubstance Abuse Concurrent With Surgery as a Possible Newly Identified Infection Risk Factor in Inflatable Penile Prosthesis Placement Based on a Retrospective Analysis of Health and Socioeconomic Factors. J Sex Med 2016;13:697-701.

54. Wilson SK, Mora-Estaves C, Egydio P, et al. Glans Necrosis Following Penile Prosthesis Implantation: Prevention and Treatment Suggestions. Urology 2017;107:144-8.

55. Althoff AD, Reeves RA, Traven SA, et al. Smoking is associated with increased surgical complications following total shoulder arthroplasty: an analysis of 14,465 patients. J Shoulder Elbow Surg 2020;29:491-6.

56. Mekhla, Borle FR. Determinants of superficial surgical site infections in abdominal surgeries at a Rural Teaching Hospital in Central India: A prospective study. J Family Med Prim Care 2019;8:2258-63.

57. Sørensen LT. Wound healing and infection in surgery. The clinical impact of smoking and smoking cessation: a systematic review and meta-analysis. Arch Surg 
2012;147:373-83.

58. Cakan M, Demirel F, Karabacak O, et al. Risk factors for penile prosthetic infection. Int Urol Nephrol 2003;35:209-13.

59. Lacy JM, Walker J, Gupta S, et al. Risk Factors for Removal or Revision of Penile Prostheses in the Veteran Population. Urology 2016;98:189-94.

60. Osmonov D, Christopher AN, Blecher GA, et al. Clinical Recommendations From the European Society for Sexual Medicine Exploring Partner Expectations, Satisfaction in Male and Phalloplasty Cohorts, the Impact of Penile Length, Girth and Implant Type, Reservoir Placement, and the Influence of Comorbidities and Social Circumstances. J Sex Med 2020;17:210-37.

61. Xuan XJ, Wang DH, Sun P, et al. Outcome of implanting penile prosthesis for treating erectile dysfunction: experience with 42 cases. Asian J Androl 2007;9:716-9.

62. Dave CN, Khalaf A, Patel HD, et al. Neurogenic bladder is an independent risk factor for complications associated with inflatable penile prosthesis implantation. Int J Impot Res 2020;32:520-4.

63. van der Sluis WB, Pigot GLS, Al-Tamimi M, et al. A Retrospective Cohort Study on Surgical Outcomes of Penile Prosthesis Implantation Surgery in Transgender Men After Phalloplasty. Urology 2019;132:195-201.

64. Pigot GLS, Sigurjónsson H, Ronkes B, et al. Surgical Experience and Outcomes of Implantation of the ZSI 100 FtM Malleable Penile Implant in Transgender Men After Phalloplasty. J Sex Med 2020;17:152-8.

65. Kocjancic E, Jaunarena JH, Schechter L, et al. Inflatable penile prosthesis implantation after gender affirming phalloplasty with radial forearm free flap. Int J Impot Res 2020;32:99-106.

66. Neuville P, Morel-Journel N, Cabelguenne D, et al. First Outcomes of the ZSI 475 FtM, a Specific Prosthesis Designed for Phalloplasty. J Sex Med 2019;16:316-22.

67. Garaffa G, Raheem AA, Christopher NA, et al. Total phallic reconstruction after penile amputation for carcinoma. BJU Int 2009;104:852-6.

68. Falcone M, Garaffa G, Gillo A, et al. Outcomes of inflatable penile prosthesis insertion in 247 patients completing female to male gender reassignment surgery. BJU Int 2018;121:139-44.

69. Gross MS, Vollstedt AJ, Cleves MA, et al. Multicenter investigation on the influence of climate in penile prosthesis infection. Int J Impot Res 2020;32:387-92.

70. Ficarra V, Novara G, Ahlering TE, et al. Systematic review and meta-analysis of studies reporting potency rates after robot-assisted radical prostatectomy. Eur Urol 2012;62:418-30.
71. Cocera R, Torremade J, Suarez JF, et al. Comparative analysis of penile implants in patients with vasculogenic erectile dysfunction versus postradical prostatectomy erectile dysfunction. Int J Impot Res 2020;32:606-10.

72. Yiou R, Binhas M. Combined Implantation of a Penile Prosthesis and Adjustable Continence Therapy ProACT in Patients with Erectile Dysfunction and Urinary Incontinence after Radical Prostatectomy: Results of a Prospective Pilot Study. J Sex Med 2015;12:2481-4.

73. Lane BR, Abouassaly R, Angermeier KW, et al. Threepiece inflatable penile prostheses can be safely implanted after radical prostatectomy through a transverse scrotal incision. Urology 2007;70:539-42.

74. Ghosh A, Somani BK. Recent Trends in Postcystectomy Health-related Quality of Life (QoL) Favors Neobladder Diversion: Systematic Review of the Literature. Urology 2016;93:22-6.

75. Loh-Doyle J, Patil MB, Sawkar H, et al. 3-Piece Inflatable Penile Prosthesis Placement Following Radical Cystoprostatectomy and Urinary Diversion: Technique and Outcomes. J Sex Med 2018;15:907-13.

76. Loh-Doyle JC, Ashrafi A, Nazemi A, et al. Dual Prosthetic Implantation After Radical Cystoprostatectomy and Neobladder: Outcomes of the Inflatable Penile Prosthesis and Artificial Urinary Sphincter in Bladder Cancer Survivors. Urology 2019;127:127-32.

77. Madbouly K, AlHajeri D, Habous M, et al. Association of the modified frailty index with adverse outcomes after penile prosthesis implantation. Aging Male 2017;20:119-24.

78. Loh-Doyle J, Patil MB, Nakhoda Z, et al. Three-Piece Inflatable Penile Prosthesis Placement Following Pelvic Radiation: Technical Considerations and Contemporary Outcomes. J Sex Med 2018;15:1049-54.

79. Dubocq FM, Bianco FJ Jr, Maralani SJ, et al. Outcome analysis of penile implant surgery after external beam radiation for prostate cancer. J Urol 1997;158:1787-90.

80. Bolat D, Topcu YK, Aydogdu O, et al. Neutrophil to Lymphocyte Ratio as a predictor of early penile prosthesis implant infection. Int Urol Nephrol 2017;49:947-53.

81. Mahon J, Dornbier R, Wegrzyn G, et al. Infectious Adverse Events Following the Placement of a Penile Prosthesis: A Systematic Review. Sex Med Rev 2020;8:348-54.

Cite this article as: Baird BA, Parikh K, Broderick G. Penile implant infection factors: a contemporary narrative review of literature. Transl Androl Urol 2021;10(10):3873-3884. doi: $10.21037 /$ tau-21-568 